Forthcoming in: Poetics.

\title{
"I like how it looks but it is not beautiful." Sensory appeal beyond beauty
}

\author{
Claudia Muth, \\ Department of General Psychology and Methodology, University of Bamberg, Germany/ \\ Forschungsgruppe EPAEG (Ergonomics, Psychological Aesthetics, Gestalt), Bamberg, \\ Germany. \\ Jochen Briesen, \\ Department of Philosophy, University of Konstanz, Germany/ Institute of Philosophy, Freie \\ Universität Berlin, Germany. \\ Claus-Christian Carbon, \\ Department of General Psychology and Methodology, University of Bamberg, Germany/ \\ Forschungsgruppe EPAEG (Ergonomics, Psychological Aesthetics, Gestalt), University of \\ Bamberg, Germany/ Bamberg Graduate School of Affective and Cognitive Sciences \\ (BaGrACS), University of Bamberg, Germany
}

\begin{abstract}
Statements such as "X is beautiful but I don't like how it looks" or "I like how X looks but it is not beautiful" sound contradictory. How contradictory they sound might however depend on the object X and on the aesthetic adjective being used ("beautiful", "elegant", "dynamic", etc.). In our study, the first sentence was estimated to be more contradictory than the latter: If we describe something as beautiful, we often intend to evaluate its appearance, whereas it is less counterintuitive to appreciate an appearance without finding it beautiful. Furthermore, statements including "beautiful" appeared more contradictory than those including "elegant" and "dynamic", pointing to its greater evaluative component. When related to artworks, sentences could appear less contradictory due to readers' consideration of the divergence between conventional beauty and art-related sensory pleasures that can even include negative valence. Such ambivalence might be more frequent in art-objects than in other artefacts. Indeed, in our study, sentences referring to artworks were estimated to be less contradictory compared to sentences referring to other artefacts. Meanwhile, an additional small group of graphic design students showed a less clear difference between art-related and non-art-related sentences. We discuss the potential influence of art experience and interest as well as theoretical and methodological challenges like the conceptualization of beauty.
\end{abstract}

Keywords: Art, Ambivalence, Expertise, beauty, Evaluative component 


\section{Introduction}

"This teacup is beautiful but I don't like how it looks" - how contradictory this sounds depends on the adjective utilized to describe the object and it might also depend on the object in question. You might have been less confused if you read "This teacup is elegant but I don't like how it looks" or "This drawing is beautiful but I don't like how it looks". Aesthetic statements ${ }^{1}$ involve an evaluation; the contrast to sensory non-appeal therefore causes a tension. We will argue that artworks allow for greater diversity of resources of pleasure than non-art artefacts: Their sensory appeal might not rely on hedonic states induced by the works' features or motives (alone) but as well on artistic values, rewarding insight in one's own experience or other art-related pleasures of the mind. This becomes evident, e.g., from appreciated artworks that depict a motive of negative valence. A reader's consideration of such possibilities of divergence might lead to reduction in how contradictory aesthetic statements of this kind appear when they refer to art instead to nonart. Familiarity with ambivalent artworks might therefore be relevant for the interpretation of such seemingly contradictory aesthetic statements.

First, we introduce the evaluative component of aesthetic statements (see 2.1), describe potential specifics of this evaluation in case the statements refer to art-related objects (see 2.2) and examine the possible role of readers' art experience (see 2.3). After presenting concrete hypotheses (see 2.4), we present an experiment that compared how contradictory different kinds of aesthetic statements appear to readers, some of them referring to artrelated objects, others to non-art artefacts (see 3). Finally, we will discuss implications and open questions (see 4).

\section{Theoretical framework}

\subsection{The evaluative component of aesthetic statements}

Aesthetic statements of the form " $\mathrm{X}$ is $\mathrm{A}$ " " $\mathrm{X}$ " representing a term referring to an object, "A" representing a positive aesthetic adjective, such as "beautiful", "elegant", "graceful", etc.) are evaluative as we express an appreciation of the object to which " $\mathrm{X}$ " refers. This is why the sentences quoted above sound contradictory. The most basic questions we can ask concerning this evaluative component are:

I) Is the evaluative component generally part of the semantic content of an aesthetic statement?

II) Is the evaluative component different for variants of aesthetic statements?

One possibility to empirically examine question I) is to analyze sentences of the following form: "X is A, but I don't like X". In this sentence the evaluative component of an aesthetic statement ("X is A") is explicitly cancelled (“..., but I don't like $X$ "). If the evaluative component is part of the semantic content, then cancelling this component should be infelicitous in the sense that " $\mathrm{X}$ is A, but I don't like X" should sound highly contradictory.

\footnotetext{
${ }^{1}$ We refer to sentences which involve an aesthetic predicate as "aesthetic statements" throughout this text.
} 
If we insert "beauty" for "A", we expect statements to appear contradictory given the conceptual overlap between beauty and liking. If we consider cases in which sensory impressions are involved, a slight variation of the mentioned sentence should make it appear even more contradictory: "X is beautiful, but I don't like how X looks or sounds." (We mention two sensory modalities only as they were included in the empirical approach; a modality-specific analysis is out of the scope of this work). If no contradiction evolves, we can assume that the evaluative component of aesthetic statements is neither part of their content as such nor is it a conventional implicature (i.e., not expressed by the sentence due to mere convention, Grice, 1989).

Consider that "beauty" refers to an object whereas "liking" refers to an individual's mental state: At least in rare cases, an object could be in conflict with criteria for (what the observer deems to be) conventional beauty (such as harmony or symmetry) but its appearance could be liked (e.g., because it is thrilling or interesting or serves as a souvenir). Marković demarcates the pleasure by beautiful features from aesthetic "pleasures of the mind" referring to a concept by Kubovy (1999) and states that "even ugly things can elicit aesthetic experience (eg, aesthetic fascination with deformation, monstrous, grotesque, morbid, horrible, and other kinds of ugliness; cf Eco 2004, 2007)" (Marković, 2012, p. 2). Pleasures of the mind are qualified by temporal patterns of emotion and intensities of these emotions (e.g., curiosity, virtuosity or surprise). Meanwhile, we should be cautious when contrasting them to beauty, because beauty can also be understood in terms of a response of an observer, shaped by the coupling between observer and environment (see also Chatterjee, 2014). Beauty can also be understood with reference to a "free beauty" (Kant, 1790/1951) as an emotion that merges meaningfulness and uncertainty with a focus on self-extension not on prevention and safety. Pleasure and liking would in contrast be related to fluent processing and a focus on security (Armstrong \& Detweiler-Bedell, 2008; see also the role of security for responses to kitsch and art; Ortlieb \& Carbon, 2019, and to innovation; Carbon, 2013). It seems plausible that pleasures of the mind potentially arise from such dynamic changes in uncertainty and meaningfulness. A rough interpretation of this rationale is that something can look or sound displeasing (e.g., by being perceptually challenging) but on the other hand beautiful as it allows for an active meaningful engagement enriching a person's mind (see also effects of ambiguity and insight on interest; Muth, Hesslinger, \& Carbon, 2015).

To further examine the relationship between beauty and sensory appeal, compare how contradictory the following two sentences appear to you:

(a1) I like how $\mathrm{X}$ looks (or sounds) but $\mathrm{X}$ is not beautiful.

(a2) X is beautiful but I do not like how X looks (or sounds).

When (a1) seems less contradictory to readers than (a2), we could infer that the sentences are not commutative and therefore beauty and sensory appeal do not amount to the same thing; in exaggerated terms: Whereas sensory appeal would be taken as a necessary condition for beauty (a2), it would not be taken as sufficient because something could be appealing without being beautiful (a1). At the same time, beauty could refer to aspects which do not strictly appeal to the senses (like thoughts or mathematical formulae, see also Chatterjee, 2014) and therefore beauty might as well combinable with sensory non-appeal.

With regard to question II), we can assume that if the level of "appearing contradictory" is a useful measure of the evaluative component, differences in this component regarding beauty and other adjectives describing an aesthetic value of $\mathrm{X}$ should be reflected by differences in how contradictory the following sentences appear: 
(a2) $\mathrm{X}$ is beautiful but I do not like how X looks (or sounds).

(b) $\mathrm{X}$ is elegant but I do not like how $\mathrm{X}$ looks (or sounds).

(c) $\mathrm{X}$ is dynamic but I do not like how $\mathrm{X}$ looks (or sounds).

\subsection{Aesthetic statements about art}

In this section, we examine potential specifics of evaluations regarding art-related objects. It is debatable whether artworks evoke aesthetic responses that are profoundly different from those to everyday objects (see e.g., discussion by Graham, 2000). An aesthetic attitude which allows for gaining sensory pleasures could generally refer to each and every object; imagine the shift in perspective when elaborating on aesthetic qualities of a rotten tree. Furthermore, aesthetic responses to art and non-art can involve conflicting emotional contents, "mixed" emotions combining positive and negative responses like when being moved (Menninghaus et al., 2015) or experiencing the shock and delight of an "Awe" experience by a sublime landscape (Konečni, 2005; but see S. Ortlieb, Fischer, \& Carbon, 2016). Meanwhile, we argue that aesthetic statements about artworks could be more easily combinable with contrasting evaluative notions than statements about other artefacts because people might consider that the sensory appearance of an artwork can be evaluated along a larger set and pattern of dimensions. These might be combinable or even include negative hedonic responses. More concretely, we base this assumption upon four broad arguments:

A) Specific values and functions applied to art. An evolutionary account describes art making as the important basic faculty of humans to "make things special" (e.g., by repetition, exaggeration, formalization, etc.) and to enjoy these creations (Dissanayake, 2009). Artistic manipulations of material or their re-contextualization often play with perceptual automatisms which guide our actions in everyday life, inducing Semantic instability (Muth \& Carbon, 2016), experiences of multistability or visual indeterminacy (not only Modern Western art, Gamboni, 2002; Krieger \& Mader, 2010). This way, an artwork could not only be valued due to what it depicts but also due to the way it heightens awareness to our own emotions or to sensory experience itself (e.g., making otherwise automatized perception itself "visible", Fiedler, 1971) with a potential transfer to our understanding and experience of the world (Graham, 2000). People might therefore often associate art with situations in which we assign value to experiential quality itself - even if it includes uncertainty, sadness or ugliness. We should note again that a reflexive experiential mode is not restricted to art, not each artwork induces it and artworks can have beautiful features and can be entertaining. Meanwhile, artworks potentially have an additional specific function: In contrast to non-art artefacts, we can for instance evaluate sensory impressions of artworks regarding both aesthetic and artistic criteria. On one hand, it is possible that sensory impressions are aesthetically pleasing but at the same time artistically of a negative value (lacking relevance, being boring, etc.). On the other hand, artworks can displease aesthetically but be of high value artistically. Having such experiences in mind, readers might estimate the sentences to appear less contradictory in case of art because artworks can be valuable despite negative hedonic responses due to the reflexive processes they evoke and the artistic values we assign to them.

B) Dichotomy of representational art. When it comes to art, we are often dealing with multiple levels of perception: e.g., when looking at representational paintings, we can focus on the material (e.g., paper and color) or on the depicted scene; more precisely: We see the scene within the material of the artwork (see Wollheim, 1982 or more recent ideas on 
"dichotomy" by Pepperell, 2015). Such dichotomous facets of experience might be perceived as valuable despite (or sometimes even because of) dis-pleasure or negative affect induced by some of the artwork's sensory features. Consider a painting of Christ on a cross. Our emotional response might be influenced by the motive's expression but we do not see and respond to Christ on a cross but instead to an artistic depiction of Christ on a cross. The dichotomy of representations allows for evaluations of the depicted motive and the way of depiction alike (material, style, virtuosity, etc.), as well as their interaction. It is for instance well possible that an artistic quality is evaluated positively despite a displeasing sujet and vice versa. Furthermore, a sujet can be presented in such a way that makes perceivers gain valuable insight about experience (see also argument A), e.g., by the selection of perspective or the distribution of detail. Sentences which combine non-appeal with different evaluative notions (beautiful, dynamic, elegant, etc.) might appear less contradictory if they refer to artworks due to this dichotomy.

C) Ambivalence in art. Ambivalent sensory pleasures are not exclusive for art but art might often promote them as well as their expectation (Muth \& Carbon, 2016; Muth et al., 2015). Pleasures of the mind are not emotions by themselves but qualified by patterns and intensities of emotions (Kubovy, 1999). We can imagine pleasurable interplays between tensions and resolutions, disturbingness and interest, semantic instabilities and insight or uncertainty and meaningfulness. Hereby, negative emotion might even be valuable as it can increase, e.g., affective intensity, involvement, attention and memory (Menninghaus et al., 2017). Negative emotions in art might not necessarily lead to aversion due a combination of a psychological distance that is induced, e.g., by the schema of art and so called embracing factors that serve to render negative emotions enjoyable and integrate them in the aesthetic experience (e.g., mixed emotions like being moved or meaning construction, Menninghaus et al., 2017). It is a highly discussed question if art provides emotion or if it heightens awareness to emotion without necessarily making us undergo these emotions (e.g., Graham, 2000). Participants sometimes report "expressed" emotions whereas they do not actually feel them given the specificity of responses to art. Something might sound sad but it does not necessarily make me sad, it might be expressive of sadness but not in each case induce sadness (Kivy, 1989; Konečni, 2008) and be attractive (e.g., Weth, Raab, \& Carbon, 2015). Meanwhile, people are indeed affected by a negative emotional connotation of a visual artwork despite its more positive evaluation in an art context (Gerger, Leder, \& Kremer, 2014). With reference to reports of genuine emotional responses by correlates in physiological measures, Menninghaus et al. (2017) conclude that negative emotions are actually felt in such aesthetic contexts, but still can be positively related with liking and enjoyment.

Whereas a transfer from ambivalent emotion to contrasting aesthetic evaluations is not straight forward, such "paradox of tragedy" (Hume, 1757/1874; see also Smuts, 2009) might be relevant when it comes to the evaluative component of aesthetic statements:

Aesthetic statements on art can reflect wether people consider the possibility of a combination between negative valence and pleasures of the mind. The specific pattern of induced pleasure might hereby vary greatly between different artworks and include contrasting dimensions; disturbing art was for instance found to be interesting but not pleasant (Turner \& Silvia, 2006). We therefore hypothesize that ambivalence might be rather typical for our conception of affective responses to art. Associations with such experiences might lead to a decrease in how contradictory sentences appear if they combine sensory pleasure with non-beauty or sensory displeasure with beauty. If these sentences refer to an artwork, then readers who are familiar with ambivalence in art will probably interpret them along the lines of " $\mathrm{X}$ induces sensory pleasures in me but no positive complex 
pleasures of the mind" or "X induces complex pleasures of the mind but no sensory pleasures in me". We expect that depending on their experience and interest in art, participants will therefore have a reading of the sentences that partially resolves the tension responsible for the felt contradiction.

D) An alternative explanation would draw upon the rather Eurocentric understanding of art prevalent in many theories and the public understanding of art (see critique by Dissanayake, 2009). People's differentiation between sentences on art vs. non-art might therefore be largely based upon Western Modern to Post-modern and Contemporary artworks that contrast conventional beauty in a pronounced manner. Accepting non-appeal as beautiful and vice versa might even serve social distinction when associating it with preference for artistic ambiguity (e.g., Krieger \& Mader, 2010).

\subsection{The role of art experience and interest}

The emotional dynamics of a person during elaboration, her appreciation of style and virtuosity, the estimation of complexity and levels of understanding and the reward by reflecting her own experience might all be affected by experience and socialization. The value assigned to the described potential dimensions - especially if they are contrasted with negative evaluative notions - therefore should be influenced by familiarity with artworks and trainings, e.g., in detecting style or theoretical background. This is reflected by studies either comparing responses before and after training or comparing responses by people with varying experience with art. It was shown that art-inexperienced participants like challenging portraits more after elaborating them (but not those that are fluently processed, Belke, Leder, \& Carbon, 2015). And training increases interest as well as comprehension of complex art, but not the structure of appraisals that evoke interest (comprehension and complexity, Silvia, 2006). Whereas art-experienced people appreciate challenge and complexity more and rather respond to structural aspects of a work of art, inexperienced people relate evaluations more often to positive emotional responses of pleasantness and warmth (Winston \& Cupchik, 1992). There is however a risk of following a normative understanding of art perception here: Rejection of conventional forms of beauty and a preference for ambiguity might also reflect goals of social distinction (as supposed by Krieger \& Mader, 2010) - this might as well account for acceptance of contrasting notions of sensory appeal and beauty.

\subsection{Hypotheses}

We conducted an empirical study which assessed how contradictory sentences appear given a variety of aesthetic adjectives and objects. Statements in the format of "I like how X looks (or sounds)" are evaluations of sensory impressions that explicitly refer to personal responses of speakers. Aesthetic statements in the format of " $\mathrm{X}$ is beautiful" do not explicitly refer to personal responses. Nevertheless, aesthetic statements of this kind often involve an evaluation of sensory impressions as well. Therefore, it seems reasonable to suppose that sentences (a1) and (a2) should appear contradictory or counterintuitive to readers:

(a1) I like how it looks (sounds), but $\mathrm{X}$ is not beautiful.

(a2) $\mathrm{X}$ is beautiful, but I do not like how it looks (sounds). 
But an object's sensory appearance could indeed be liked without being beautiful because there are various pleasures of the mind which potentially include or exclude beauty. This might not only account for functional or conceptual aspects but also comprise qualities of sensory appearance. At the same time, beauty might either describe a match to standards for pleasing attributes or a kind of challenging meaningfulness. In some cases it might also refer to non-sensory aspects of an object (e.g., a thought can be beautiful). An object can therefore also be beautiful despite a non-appealing sensory appearance.

Given the lack of conceptual clarity regarding "beauty" and the fact that objects might be visually (auditorily) appealing for various reasons, we compare responses to both sentential formats in an exploratory manner without a directed hypothesis. Four outcomes are possible: First, suppose both (a1) and (a2) are not considered to be contradictory at all, then personal sensory appeal would be neither necessary nor sufficient for classifying an object as beautiful. Second, suppose (a1) and (a2) are both considered to be highly contradictory, then this would suggest that personal sensory appeal would be necessary and sufficient for classifying something as beautiful. In this case sensory appeal and beauty would more or less amount to the same thing. Third, suppose (a1) is judged to be highly contradictory whereas (a2) is not, then sensory appeal would be sufficient for X to be classified as beautiful, but it would not be necessary. In this case, even though people tend to classify every sensory appealing object as beautiful, they still allow for beautiful objects that are not appealing to the senses. Fourth, (a2) is judged to be highly contradictory whereas (a1) is not, then sensory appeal would be necessary for $\mathrm{X}$ to be classified as beautiful, but it would not be sufficient. In this case people would take sensory appeal as a precondition for beauty, but take beauty not to be exhausted by sensory appeal. In other words, they would consider cases of sensory appeal beyond beauty.

Furthermore, we tested how contradictory sentences appear when "beautiful" is exchanged by other aesthetic adjectives, namely "elegant" and "dynamic":

(b) $\mathrm{X}$ is elegant but I do not like how it looks (or sounds).

(c) $\mathrm{X}$ is dynamic but I do not like how it looks (or sounds).

We hypothesized that "beautiful" contains a larger evaluative component than those other adjectives and that therefore (a2) yields higher values regarding contradiction than (b) and (c) (Hypothesis 1). We chose only two further adjectives and forwent to test corresponding sentences to the format of (a1) in order to avoid potential fatigue during the evaluation of the sentences.

Additionally, we suggest that "X is beautiful" and "I like how it looks (or sounds)" can have different readings - especially if "X" refers to an artwork. "I like how X looks (or sounds)" can be understood as referring to (i) simple sensory appeal or (ii) to higher and more complex pleasures of the mind induced by sensory features of the artwork (see section 2.2). Analogously, " $X$ is beautiful" might also be understood (i) as referring to sensory features of the artwork that induce simple sensuous pleasures or (ii) as referring to features that induce more elaborated and complex pleasures of the mind. Note that in this case these features might comprise non-sensory aspects (think of concept art or participatory art) as well as sensory aspects (think of the dichotomy between motive and material composition or artistic and stylistic values). Given that the same is true with respect to the corresponding negations of the sentences "I do not like how it looks (or sounds)" and "X is not beautiful", there are some possible readings of the sentences (a1) and (a2) that are not contradictory. With respect to (a1), for example, such readings are: 
(a1') X induces simply sensuous pleasure in me (see (i)), but it does not have features (sensory or non-sensory) that induce more complex pleasures of the mind (see (ii)).

(a1'") $X$ induces complex pleasures of the mind in me due to its sensory features (see (ii)), but it does not induce simple sensuous pleasure in me (see (i)).

Given that artworks often induce pleasures of the mind despite displeasing sensory attributes and considering people's reflections on experiences with such ambivalence, such noncontradictory readings of the sentences should be more easily available if the sentences refer to artworks. Therefore, we hypothesize that the sentences to be tested appear less contradictory if they refer to artworks (Hypothesis 2).

Finally, the difference between art-related and non-art-related sentences might be pronounced when people are more familiar with art. Their understanding of art might be dominated by Western Modern to Contemporary "high" art which contrasts hedonic and sensuous pleasure in many cases. Stating its sensory-appeal might furthermore serve social distinction via the rejection of conventional forms of beauty. In addition, people with low experience were reported to show a tendency to focus on pleasingness of features and not on style or structure when evaluating art. This could increase the perceived contradiction when pleasure of the mind collides with sensory displeasing attributes. Thus, for art-experienced readers, non-contradictory readings of the sentences (i.e., readings along the lines of (a1') and (a1")), should be more easily available. We therefore hypothesized lower ratings of how contradictory the sentences appear to people with higher experience with and interest in art (Hypothesis 3).

In summary, the explorative question and specific hypotheses to be tested are:

Explorative question: How contradictory do the following sentences appear to readers: (a1) "I like how X looks (sounds) but it is not beautiful"; (a2) "X is beautiful, but I don't like how X looks (sounds)."

Hypothesis 1: (a2) "X is beautiful, but I don't like how X looks (sounds)" appears more contradictory to readers than (b) "X is dynamic, but I don't like how X looks (sounds)" and (c) "X is elegant, but I don't like how X looks (sounds)".

Hypothesis 2: All sentences appear less contradictory if " $\mathrm{X}$ " is an art-related concept.

Hypothesis 3: All sentences appear even less contradictory if " $\mathrm{X}$ " is an art-related concept and if readers are highly experienced with and interested in art."

\section{Method}

\subsection{Participants}

Forty participants took part in the study and were tested individually in an experimental lab of the University of Bamberg ( 31 female, 8 male, 1 other; $M_{\text {age }}=26.7$ years; $S D_{\text {age }}=8.8$; range $_{\text {age }}=17-51$ years; referred to as "non-trained participants" in the following). Thirty of them were students of psychology-they gained course credit for their participation. The other participants were recruited via word of mouth from the general public. A Snellen eye chart test and a subset of the Ishihara color cards ensured that they had normal or corrected- 
to-normal vision. In addition, we tested 14 undergraduate students of graphic design at the Akademie Faber-Castell, Stein/Germany, in a group setting at the beginning of a seminar (referred to as "trained participants" in the following). Data of one participant was excluded from the analyses due to a complete lack of replies to the questionnaire on art experience and interest (remaining 13 participants: 9 female; $M_{\mathrm{age}}=22.0$ years; $S D_{a g e}=2.2$; range $_{\mathrm{age}}=19$ 27 years). All participants were naïve to the purpose of the study.

\subsection{Stimuli}

We presented 56 sentences in random order, consisting of 14 exemplars of each of the following formats:

(a1) I like how X looks (sounds) but $\mathrm{X}$ is not beautiful.

(a2) $\mathrm{X}$ is beautiful, but I don't like how $\mathrm{X}$ looks (sounds).

(b) $\mathrm{X}$ is dynamic, but I don't like how $\mathrm{X}$ looks (sounds).

(c) $\mathrm{X}$ is elegant, but I don't like how $\mathrm{X}$ looks (sounds).

$\mathrm{X}$ was replaced by seven art-related concepts (installation, artwork, song, sculpture, collage, painting, drawing) and seven concepts of non-art artefacts (lamp, jacket, table, closet, bicycle, vase, basic commodity). If "song" was included, we wrote "... how the song sounds".

\subsection{Procedure}

Participants evaluated the sentences one after the other via a 7-point-scale on the "level of appearing contradictory", as we will call it in the following. The original question in German was: "Wie widersprüchlich klingt dieser Satz?" ("How contradictory does this sentence sound?"). Before evaluation, they read an instruction elaborating on the intended meaning of "contradictory" (see Table A1 in Appendix). After each set of 14 sentences, participants had the opportunity to pause and relax. Finally, each participant filled in a questionnaire on experience with and interest in art.

\section{Results}

Please find the data via Open Science Framework: https://osf.io/bak65/?view_only=a383541 fae704caaba43b39a81ca2e31. Based on their answers to the questionnaire on art experience and interest, we built a score of art experience and interest for each participant. It was composed of the following three subscales: A) artistic practice (average out of artistic activity: "yes" $=2 /$ "no" $=0$ and competence in drawing: "yes"=2/ "no"=0), B) art interest (average out of enjoyment of art history course in school: "very much" $=2$, "a little" $=1$, "not at all" $=0$ and intent to visit art exhibitions during the next year: "more than 3 times" $=2$ / "more than once" $=1$ / "none"=0) and C) art experience (average of frequency of visits to exhibitions last year: "more than 3 times" $=2$ / "more than once" $=1$ / "none" $=0$, estimation of having an eye for art: "yes"=2 / "no" $=0$ and having read a book on art: "yes" $=2$ / "no" $=0$ ). We assigned non-trained 
participants to two groups based on a median split of data: 20 of them scoring low on art experience and interest $(M=.40, S D=.28), 20$ scoring high $(M=1.49, S D=.419)$. The 13 graphic design students scored slightly higher on art experience and interest $(M=1.63$., $S D=.25)$.

Given the specific background, experience and motivation of graphic design students we interpreted them as stemming from a different population than the non-trained students. Consequently, we report their data separately. Five ratings were excluded from the analysis of non-trained participants due to response times that were far from those of a gut feeling response, even when considering reading and elaboration $(>40 \mathrm{~s})$. We averaged all other ratings of level of appearing contradictory by non-trained participants across stimuli and compared these average values for each of the sentential formats via a mixed-design ANOVA with format (a1 vs. a2 vs. b vs. c) and category (art vs. non-art) as withinparticipants factors and art experience and interest (low vs. high) as between-participants factor. It revealed a large main effect of format $-F(3,114)=41.37, p<.001, \eta_{\mathrm{p}}{ }^{2}=.521-\mathrm{a}$ small main effect of category- $F(1,38)=5.37, p=.03, \eta_{\mathrm{p}}{ }^{2}=.124-$ and a small interaction effect between format and category $-F(3,114)=3.94 ; p=.01, \eta_{\mathrm{p}}{ }^{2}=.094$. Before turning to differences between participants, we will discuss the specific pattern for sentential formats and object-categories.

Simple main effects revealed significant differences between all sentential formats for non-trained participants (see Figure 1). We found lower ratings for sentences that imply sensory appeal despite non-beauty (a1) than sentences implying a beautiful object of no sensory appeal (a2). Sentences combining sensory non-appeal with beauty (a2) appeared more contradictory than those including other evaluative adjectives $(b, c)$. As hypothesized, sentences referring to art-related concepts were generally estimated as slightly less contradictory $(M=3.24, S D=.96)$ than those referring to non-art artefacts $(M=3.44, S D=.83)$, this difference was significant as revealed by a paired $t$-test: $t=-2.29, p=.03$, Cohen's $d=0.362$. This was mainly due to differences for sentential formats (a1) and (b) whereas for formats (a2) and (c) the difference was non-significant (see Figure 1). As simple main effects in Table 1 show, $b$ and $c$ were similarly contradictory for non-art, whereas for artrelated concepts the difference was significant.

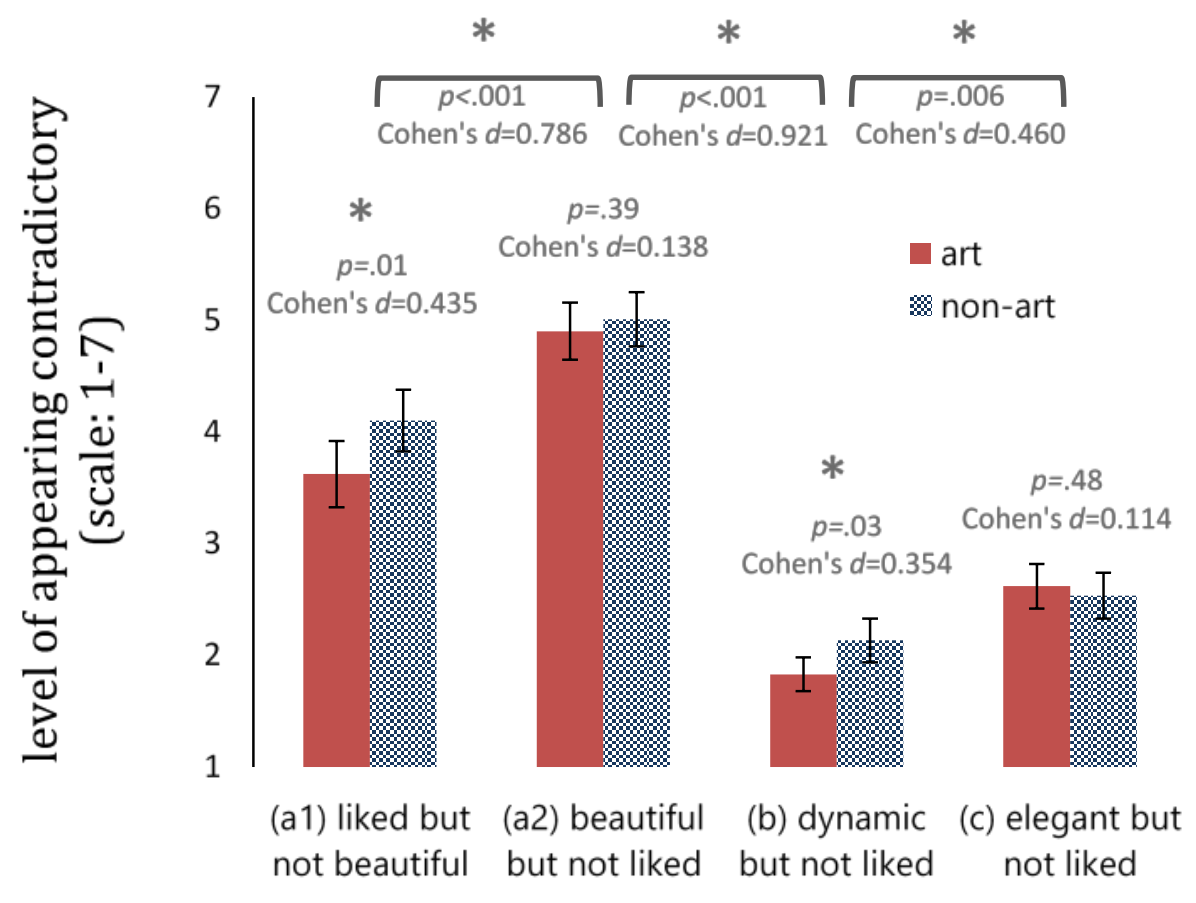


Figure 1. Average level of appearing contradictory for different sentential formats and context categories based on evaluations by non-trained participants. Significant differences (Simple main effects) are marked by an asterisk. Note that further differences were significant (all $p<.001$ ) - those between (a1) and (b), (a1) and (c), (a2) and (b), and (a2) and (c). Error bars represent \pm 1 SEM.

Table 1. Simple main effects, Bonferroni-adjusted. Significant differences are in bold.

art

comparisons

$\triangle \quad$ SEM $\quad p \quad$ Cohen's $d$

(a1) liked but $\quad$ vs. (a2) beautiful

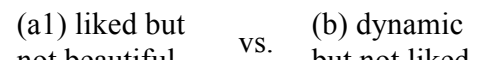

not beautiful vs. but not liked

$\begin{array}{lll}1.79 & .31 & <.001\end{array}$

0.901

0.404

(a1) liked but

not beautiful

vs. (c) elegant

vs. but not liked

$1.00 \quad .38$

.073

$\begin{array}{ll}3.07 & .29\end{array}$

$<.001$

1.670

but not liked

vs. (b) dynamic

but not liked

(a2) beautiful

vs. (c) elegant

but not liked

vs. but not liked

2.

(b) dynamic

but not liked

vs. (c) elegant

vs. but not liked

$-.79 \quad .19$

.001

0.647

1.262

non-art

$\triangle \quad S E M \quad p \quad$ Cohen's $d$

$\begin{array}{lllll}1.97 & .37 & <.001 & 0.855\end{array}$

$\begin{array}{lllll}1.57 & .39 & .002 & 0.625\end{array}$

$\begin{array}{llll}2.88 & .36 & <.001 & 1.270\end{array}$

$\begin{array}{llll}2.48 & .29 & <.001 & 1.340\end{array}$

$\begin{array}{llll}-.40 & .24 & 0.59 & 0.259\end{array}$

We hypothesized that art experience and interest might be relevant for the level of appearing contradictory when sentences referred to artworks. Art experience and interest was a significant factor for level of appearing contradictory on its own as evident from the ANOVA $-F(1,38)=7.27, p=.01 ; \eta_{\mathrm{p}}{ }^{2}=.161$. The interaction with category was nonsignificant $-F(1,38)=1.85, p=.18, \eta_{\mathrm{p}}{ }^{2}=.046$ and the three-way interaction between format, category, and art experience and interest was a non-significant trend $-F(3,114)=2.41$, $p=.07, \eta_{\mathrm{p}}{ }^{2}=.060$.

Figure 2 shows that for non-trained people with high scores in art experience and interest sentences appeared less contradictory if they referred to art (see Figure A1 in Appendix for diagrams regarding the other sentential formats). This difference was significant only for sentential format al (note again that the 3-way-interaction was a trend only). The graphic design students, however, differentiated less between art and non-art sentences. Given their low number of $n=13$, we did not conduct inference statistical analyses on their data. 

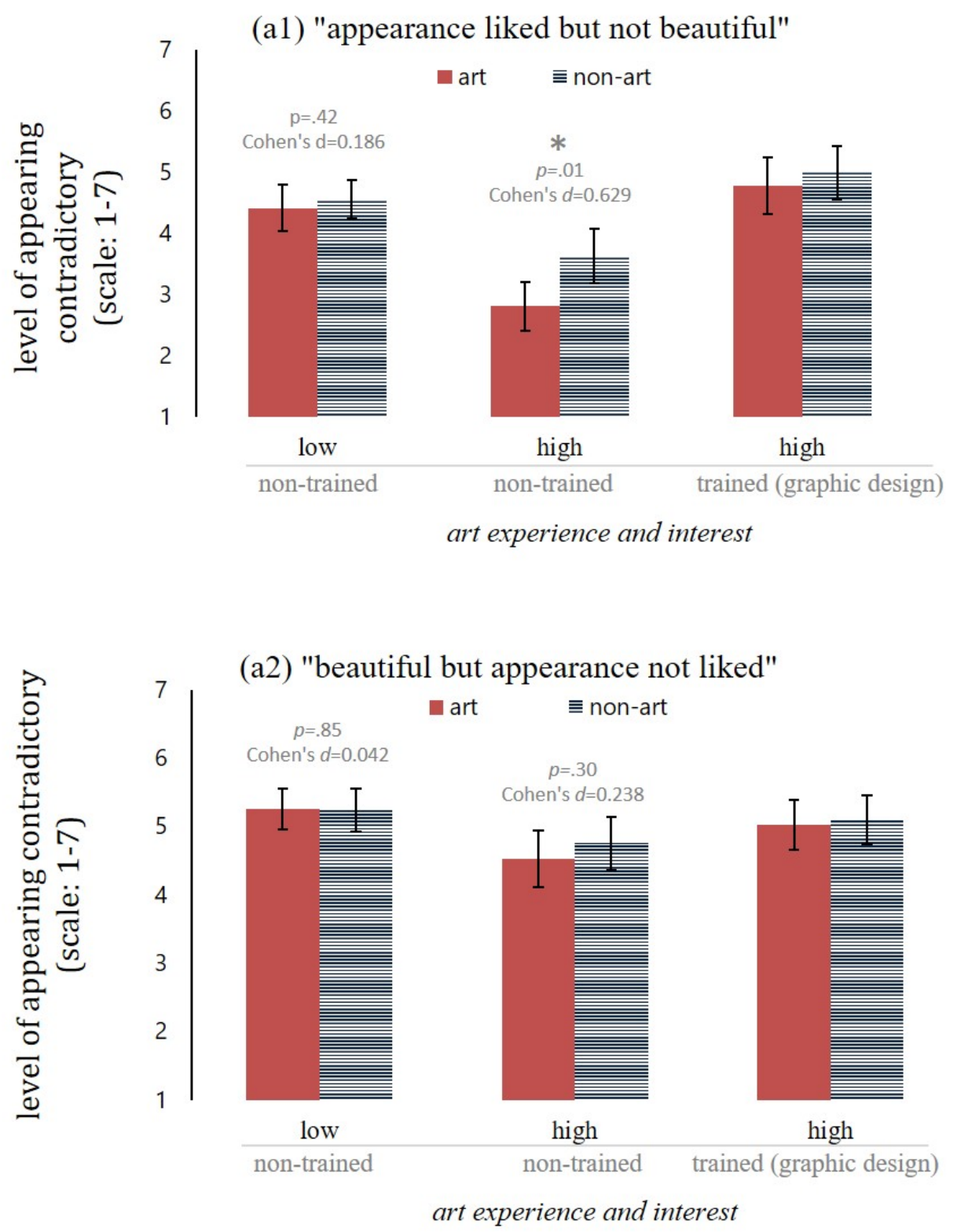

Figure 2. Level of appearing contradictory for two sentential formats (a1) and (a2), concepts related to art or non-art and three groups of participants based on estimations of art experience and interest and training in Graphic design. Significant differences (Simple main effects) between object categories for each group of participants are marked by an asterisk. Error bars represent $\pm 1 S E M$. See Figure A1 in Appendix for diagrams regarding sentential formats (b) and (c).

Further analyses reveal that the relevance of art experience and interest might be driven by few cases only: Figure 3 shows each participant's score in art experience and interest and the averaged difference in appearing contradictory between non-art vs. artrelated sentences (positive scores represent less contradiction for art-related concepts). A weak positive correlation of non-trained persons' art experience and interest with that difference describes how art-related sentences were rated as slightly less contradictory by people with high art experience and interest $(r=.38, p=.02)$. But only three participants with high experience and interest in art judged sentences referring to art-related objects much less contradictory than those referring to non-art and one participant of moderate art experience and interest judged them as much more contradictory (see lighter circles in Figure 3). When 
excluding data by these participants, the correlation dissolves $(r=.17, p=.31)$. In addition, we plotted corresponding data by trained participants (graphic design students) who did not show larger divergence between ratings of art- and non-art-sentences despite their high scores in art experience and interest.

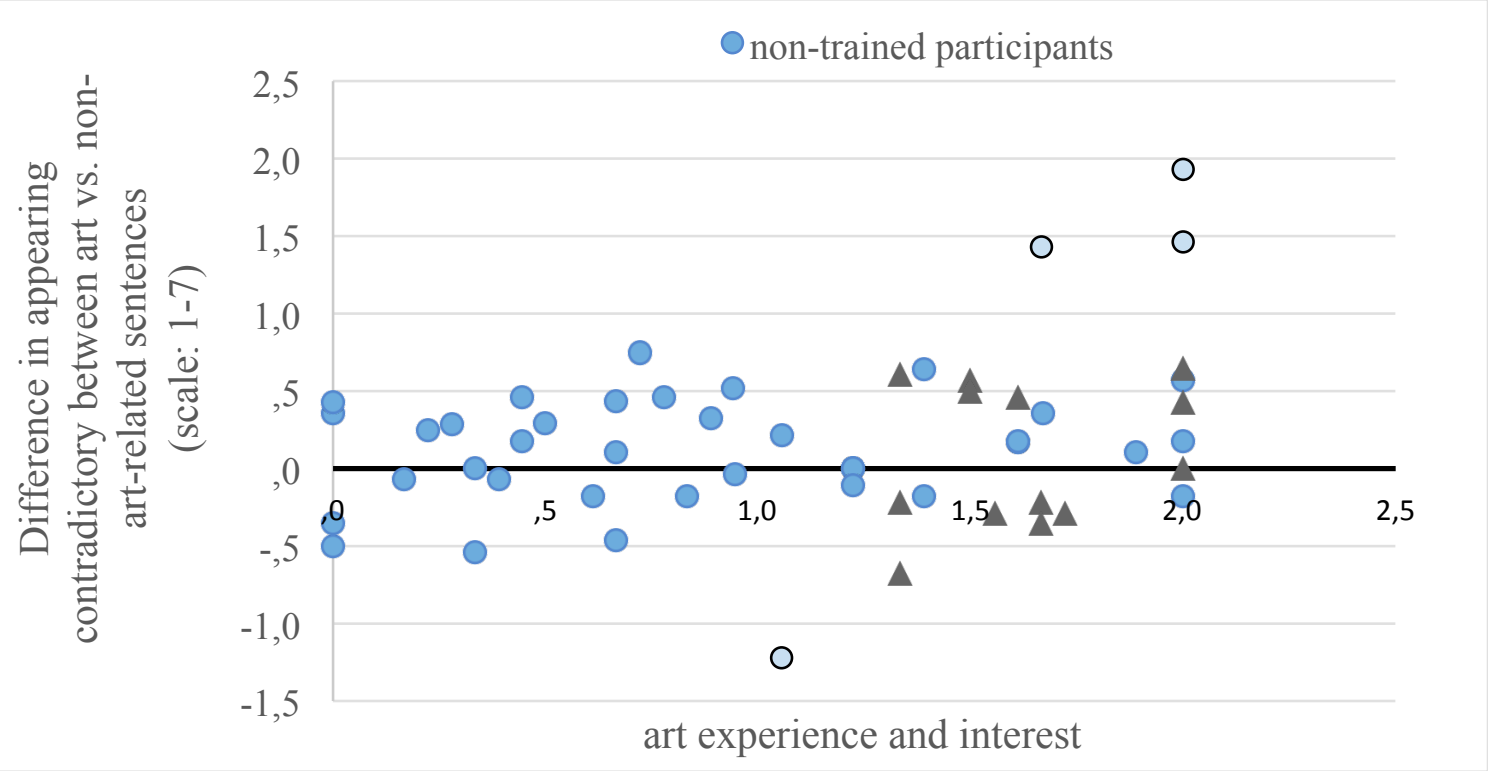

Figure 3. Individual scores in art experience and interest and difference in appearing contradictory for non-art vs. art-related sentences, averaged for each participant (positive scores $=$ less contradiction for art-related concepts). Outliers are marked by lighter color.

\section{Discussion}

We examined the evaluative components of aesthetic statements by assessing how contradictory people rate notions combining non-appealing sensory appearance with beauty, elegance or dynamics and notions combining sensory appeal with non-beauty. (a1) "I like how X looks but it is not beautiful" appeared less contradictory than (a2) "X is beautiful but I don't like how it looks". This indicates that people rather accept that an object can be of a sensory appeal without being beautiful given the multiplicity of potential sensory pleasures of the mind, whereas beauty would rather imply sensory appeal. Such a comparison was exploratory given the lack of clear conceptualization of beauty which can refer to sensory as well as non-sensory aspects and can either be understood as "conforming to beauty standards" or as an emotion linked with uncertainty and meaningfulness without the necessity of sensory appeal. Note as well that the combination of sensory appeal and nonbeauty was not perfectly intuitive: Statements in the format of (a1) were evaluated as moderately contradictory. This finding therefore requires further examination.

"X is beautiful, but I don't like how X looks (sounds)" appeared more contradictory than "X is dynamic, but I don't like how $\mathrm{X}$ looks (sounds)" and " $\mathrm{X}$ is elegant, but I don't like how X looks (sounds)", pointing to the larger evaluative component of "beauty" (Hypothesis 1). We furthermore suggested that artworks can be of sensory appeal due to a wider range of evaluative dimensions than non-art artefacts - sometimes even despite or due to displeasing or non-beautiful attributes or motives. We therefore hypothesized that nonbeauty and sensory appeal (and potentially also beauty and sensory non-appeal) are more easily combinable in sentences about art than in those about non-art due to people's 
associations with encounters with ambivalent experiences of art (Hypothesis 2). When sentences referred to artworks, they indeed appeared slightly less contradictory to participants - this effect was mainly driven by sentential format (a1) "I like how X looks (sounds) but $\mathrm{X}$ is not beautiful" and (b) "X is elegant but I do not like how $\mathrm{X}$ looks (sounds)". It was not significant for (a2) "X is beautiful, but I don't like how X looks (sounds)" and (c) "X is dynamic but I do not like how X looks (sounds)". It seems that also for art, people consider sensory appeal as being important for beauty, whereas it appears less contradictory to judge art as non-beautiful but of sensory appeal than for other artefacts.

We further hypothesized that the difference between art- and non-art-related sentences would be pronounced for participants with high experience with and interest in art because they might be especially familiar with artworks that are ambivalent regarding beauty and sensory appeal and more focused on style or structure instead of pleasingness (Hypothesis 3). People with high experience and interest in art indeed rated sentences combining sensory appeal with non-beauty (a1) as less contradictory if they referred to art than to non-art. But in contrast to our hypothesis, the interaction between art experience and interest, sentential format and category was a non-significant trend only. Also, an additional group of Graphic design students did not seem to differentiate in a similar manner between art-related and non-art-related sentences although they scored high in art experience and interest. A visualization of average differences for each participant furthermore shows that only three art-experienced participants rated art-related sentences considerably less contradictory than those on non-art. Instead, people with high art experience and interest rated sentences to be less contradictory in general irrespective of their connection with art.

It is well possible that participants had various concepts of beauty in mind during the task. Some notions of beauty refer to rather universal beauty standards (Grammer, Fink, Møller, \& Thornhill, 2003) or associate it with pleasingness (e.g., Reber, Schwarz, \& Winkielman, 2004), whereas others separate it from pleasingness and refer to a "free" beauty (Kant, 1790/1951), potentially involving challenge and promised meaningfulness (Armstrong \& Detweiler-Bedell, 2008). Also, people might have thought about cases in which beauty is utilized in order to describe non-sensory aspects (a beautiful idea, etc.). Whereas additional (qualitative) approaches might be suitable to further examine which forms of beauty and appeal are considered when thinking about the presented sentences, our findings can be understood as a reflection of an important differentiation between hedonic states and aesthetic pleasures of the mind induced by art. Other expressions than "I like how $\mathrm{X}$ looks (sounds)" might reveal further differences in how contradictory sentences appeared if they referred to art vs. non-art. It would be interesting to additionally include adjectives that relate to negative and positive emotions in a variety of ways - we could for instance state "I am fascinated by X but it is not beautiful", "I like how X looks, but it is not thrilling", " $X$ is beautiful, but it did not surprise me" or " $X$ is beautiful, but it did not touch me". It would hereby be promising to utilize combinations of adjectives that have been extracted from evaluations of paintings as the two separate (non-correlated) factors of affective tone (e.g., lovely or appealing) and aesthetic experience (e.g., awing or exceptional, Marković, 2010).

Pleasures of the mind can be attributed to many episodes in life, not only to those with art. We need to consider that by presenting the contradictory sentences during our study, we might have induced an "aesthetic" mindset that made people think about alternative sensory pleasures beyond beauty for all kinds of artefacts, also non-art - e.g., by thinking about appreciated visual features of a design that do not please in a conventional manner. Another shortcoming of our approach is that the mere combination of some adjectives with non-art artefacts can sound unusual; e.g., a jacket can be judged concerning 
its "elegance" but rather rarely concerning its "dynamics". Part of the estimations for "elegant" and "dynamic" might therefore stem from this unusualness, not from the evaluative component of the utilized adjectives alone. Again, qualitative methods should further complement our approach to explore which aspects might have induced how contradictory sentences appear.

It seems important to note that a slightly decreased level of appearing contradictory for sentences referring to art-related objects does not imply that sentences did not sound contradictory at all: Instead, the moderate to high average estimates either point to the rareness in which sensory appeal collides with non-beauty and beauty with sensory nonappeal or the low awareness to the very common usage of negative affect in the arts (for such an argument in case of negative emotions see Menninghaus et al., 2017). Meanwhile, we need to consider the possibility that people are familiar with but are not aware of an object's contrasting effects on pleasure in many cases. Whereas our method provides an intuitive access to specifics of the sensory appeal of non-beauty for different categories of objects, it is crucial to note that we measured responses to sentences about objects, not to objects themselves (neither in different contexts and different modes). The method is limited by the available associations and reflections of people's own experience when confronted with these sentences.

We can only speculate at this point that a greater number of associations with encounters with art might strengthen the awareness that sensory appeal and non-beauty can co-exist, e.g., by a training to shift one's focus from represented content to composition and material, encounters with extreme cases of pleasing non-beauty, or by explicit art theoretical discussions of the ambivalence between both. Meanwhile, we did not find a clear effect of art experience and interest on the divergence between statements on art and non-art based on our data. The difference in how contradictory sentences (a1) on art vs. non-art appeared might also reflect a focus on Western Modern to Post-Modern and Contemporary artworks that are associated with ambiguity and contrasts to conventional hedonic pleasure (see also considerations by Dissanayake, 2009; and Krieger \& Mader, 2010). Social distinction by rejection of conventional forms of beauty due to such an understanding of "high art" might also be a reason for reduced levels of appearing contradictory. These motives might account for people of high education in general irrespective of a specialization in the aesthetic domain. Furthermore, we cannot exclude that our non-standardized questionnaire is confounded with other characteristics of the participants (e.g., states or traits) that might allow for various explanations for this effect (such as differences in level of education). For graphic design students, the category of objects (art/non-art) did not affect how contradictory sentences appeared and their ratings were generally high when compared to other participants with high scores on art experience and interest. This makes us cautious about any strong interpretation of the relevance of art experience and interest for the described effects. It is furthermore possible that different kinds of engagement with aesthetic objects can lead to different criteria for their evaluation. It would be highly interesting to see if graphic designers might be slightly biased towards valuing generally accepted aesthetic properties of images and objects and less focused on other potential pleasures of the mind which might not be accepted by clients and potential customers. 


\section{Conclusion}

"Beautiful" contains a large evaluative component: If we describe something as beautiful, we often intend to evaluate its appearance. But various pleasures of the mind can cause sensory appeal, even in contrast to beauty. Aesthetic statements such as

(a1) I like how $\mathrm{X}$ looks (sounds), but $\mathrm{X}$ is not beautiful,

appear slightly less contradictory if they refer to art. Presupposed that statements on art actually reflect people's experiences with art, our findings might point to relevance of negative valence (e.g., Konečni, 2005; Menninghaus et al., 2017), dichotomy between content and material (Pepperell, 2015), contrasts between aesthetic and artistic criteria as well as ambivalence and ambiguities (Muth \& Carbon, 2016) when it comes to art.

Meanwhile, we need to consider that personal differences in experience might have an effect on the consideration of combinations of non-beauty with sensory appeal and sensory nonappeal with beauty. 


\section{Appendix}

Figure A1. Level of appearing contradictory for two sentential formats (b) and (c), concepts related to art or non-art and three groups of participants based on estimations of art experience and interest. Error bars represent \pm 1 SEM.
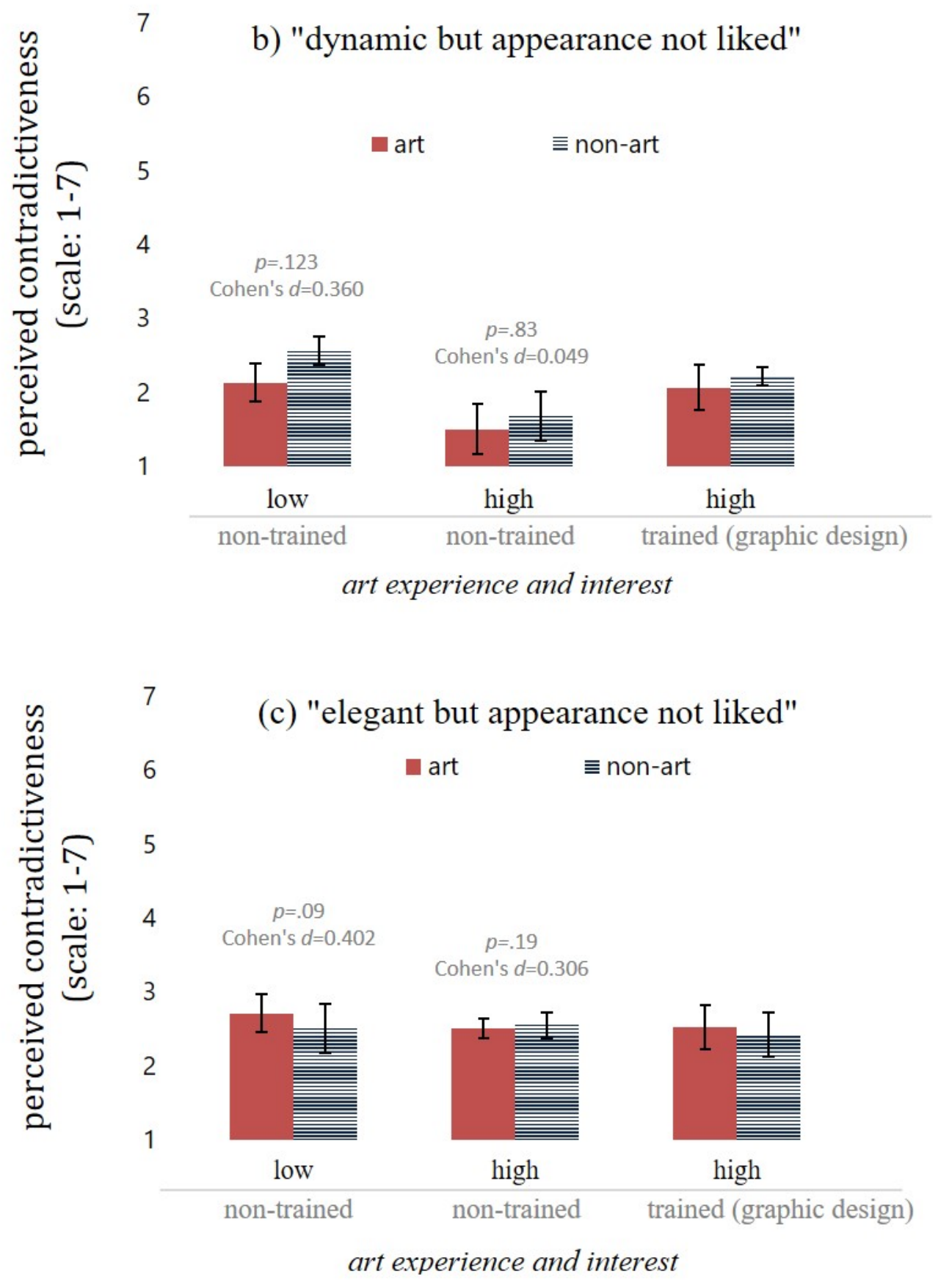
Statements on appeal of non-beauty

Table A1. Instruction before the sentences' evaluation (original and translated).

\section{Instruction}

original

Wir präsentieren dir im Folgenden verschiedene Sätze, die dir mehr oder weniger merkwürdig erscheinen werden. Wir interessieren uns dafür, wie widersprüchlich sie dir erscheinen.

Der Begriff der "Widersprüchlichkeit" ist hier weit gefasst: Er beschreibt die Wirkung eines Satzes, der auf irgendeine Art absurd oder merkwürdig "klingt". Schätze bitte auf einer Skala von 1-7 ein, wie stark widersprüchlich dir der aktuelle Satz erscheint und drücke eine entsprechende Taste: 1 ist "gar nicht widersprüchlich" und 7 "sehr widersprüchlich". Es gibt hierbei keine richtigen oder falschen Antworten, bewerte bitte einfach spontan, wie der Satz auf dich wirkt. translated

In the following, we will present sentences which sound more or less strange to you. It is interesting to us, how contradictory they appear to you.

Hereby, the concept of ,contradictory“ is broad: It describes the effect of a sentence that sounds absurd or strange in some way. Please estimate on a scale of 1-7 how contradictory the current sentence appears to you and press a corresponding key: 1 is "not at all contradictory" and 7 "very contradictory". There are no right or wrong answers, please just rate spontaneously how the sentence appears to you. 


\section{Acknowledgements}

\section{References}

Armstrong, T., \& Detweiler-Bedell, B. (2008). Beauty as an Emotion: The Exhilarating Prospect of Mastering a Challenging World. Review of General Psychology, 12(4), 305-329. doi: 10.1037/a0012558

Belke, B., Leder, H., \& Carbon, C. C. (2015). When challenging art gets liked: Evidences for a dual preference for-mation process for fluent and non-fluent portraits. PlosOne, 10(8), e0131796. doi: 10.1371/journal.pone.0131796

Carbon, C. C., Faerber, S., Gerger, G., Forster, M., \& Leder, H. (2013). Innovation is Appreciated When We Feel Safe: On the Situational Dependence of the Appreciation of Innovation. International Journal of Design, 7(2), 43-51.

Chatterjee, A. (2014). The aesthetic brain. How we evolved to desire beauty and enjoy art. New York: Oxford.

Dissanayake, E. (2009). The artification hypothesis and its relevance to cognitive science, evolutionary aesthetics, and neuroaesthetics. Cognitive Semiotics, 5(Special Issue on Aesthetic Cognition), 148-173.

Fiedler, K. (1971). Schriften zur Kunst. Munich: Fink.

Gamboni, D. (2002). Potential images: Ambiguity and indeterminacy in modern art. London: Reaktion Books.

Gerger, G., Leder, H., \& Kremer, A. (2014). Context effects on emotional and aesthetic evaluations of artworks and IAPS pictures. Acta Psychologica, 151, 174-183. doi: https://doi.org/10.1016/j.actpsy.2014.06.008

Graham, G. (2000). Philosophy of the arts. London: Routledge.

Grammer, K., Fink, B., Møller, A. P., \& Thornhill, R. (2003). Darwinian aesthetics: sexual selection and the biology of beauty. Biological Reviews, 78(3), 385-407. doi: $10.1017 / \mathrm{S} 1464793102006085$

Grice, H. P. (1989). Studies in the Way of Words. Cambridge: Harvard University Press.

Hume, D. (1757/1874). On Tragedy. In T. H. Green \& T. H. Grose (Eds.), The Philosophical Works of David Hume (Vol. 3). London: Longman.

Kant, I. (1790/1951). Critique of judgment. New York: Hafner.

Kivy, P. (1989). Sound sentiment: An essay on the musical emotions. Philadelphia: Temple University Press.

Konečni, V. J. (2005). The aesthetic trinity: Awe, being moved, thrills. Bulletin of Psychology and the Arts, 5, 27-44.

Konečni, V. J. (2008). Does music induce emotion? A theoretical and methodological analysis. Psychology of Aesthetics, Creativity, and the Arts, 2, 115-129.

Krieger, V., \& Mader, R. (2010). Ambiguität und Kunst - Typen und Funktionen eines ästhetischen Paradigmas. Wien, Köln, Weimar: Böhlau.

Kubovy, M. (1999). On the Pleasures of the Mind. In D. Kahneman, E. Diener \& N. Schwarz (Eds.), Well-being. The Foundations of Hedonic Psychology (pp. 134-154). New York: Russell Sage Foundation.

Marković, S. (2010). Aesthetic experience and the emotional content of paintings. Psihologija, 43(1), 43-60.

Marković, S. (2012). Components of aesthetic experience: aesthetic fascination, aesthetic appraisal, and aesthetic emotion. i-Perception, 3(1), 1-17. doi: 10.1068/i0450aap 
Menninghaus, W., Wagner, V., Hanich, J., Wassiliwizky, E., Jacobsen, T., \& Koelsch, S. (2017). The Distancing-Embracing model of the enjoyment of negative emotions in art reception. Behavioral and Brain Sciences, 40, e347. doi: $10.1017 / \mathrm{s} 0140525 \times 17000309$

Menninghaus, W., Wagner, V., Hanich, J., Wassiliwizky, E., Kuehnast, M., \& Jacobsen, T. (2015). Towards a psychological construct of being moved. PLoS ONE, 10(6), e0128451. doi: 10.1371/journal.pone.0128451

Muth, C., \& Carbon, C. C. (2016). SeIns: Semantic Instability in Art. Art \& Perception, 4(12), 145-184. doi: 10.1163/22134913-00002049

Muth, C., Hesslinger, V., \& Carbon, C. C. (2015). The appeal of challenge in the perception of art: How ambiguity, solvability of ambiguity and the opportunity for insight affect appreciation. Psychology of Aesthetics, Creativity, and the Arts, 9, 206-216.

Ortlieb, S., Fischer, U. C., \& Carbon, C. C. (2016). Enquiry into the Origin of Our Ideas of the Sublime and Beautiful: Is there a Male Gaze in Empirical Aesthetics? Art \& Perception, 4, 205-224.

Ortlieb, S. A., \& Carbon, C.-C. (2019). A Functional Model of Kitsch and Art: Linking Aesthetic Appreciation to the Dynamics of Social Motivation. [Hypothesis and Theory]. Frontiers in Psychology, 9(2437). doi: 10.3389/fpsyg.2018.02437

Pepperell, R. (2015). Artworks as dichotomous objects: implications for the scientific study of aesthetic experience. Frontiers in Human Neuroscience, 9(295). doi: 10.3389/fnhum.2015.00295

Reber, R., Schwarz, N., \& Winkielman, P. (2004). Processing fluency and aesthetic pleasure. Is beauty in the perceiver's processing experience? Personality and Social Psychology Review, 8(4), 364-382. doi: 10.1207/s15327957pspr0804_3

Silvia, P. J. (2006). Artistic Training and Interest in Visual Art: Applying the Appraisal Model of Aesthetic Emotions. Empirical Studies of the Arts, 24(2), 139-161. doi: 10.2190/dx8k-6wea-6wpa-fm84

Smuts, A. (2009). Art and Negative Affect. Philosophy Compass, 4(1), 39-55.

Turner, S. A. J., \& Silvia, P. J. (2006). Must interesting things be pleasant? A test of competing appraisal structures. Emotion, 6, 670-674. doi: 10.1037/15283542.6.4.670

Weth, K., Raab, M. H., \& Carbon, C. C. (2015). Investigating emotional responses to selfselected sad music via self-report and automated facial analysis. Musicae Scientiae, 19(4), 412-432. doi: 10.1177/1029864915606796

Winston, A. S., \& Cupchik, G. C. (1992). The Evaluation of High Art and Popular Art By Naive and Experienced Viewers. Visual Arts Research, 18(1), 1-14.

Wollheim, R. (1982). Objekte der Kunst. Frankfurt: Suhrkamp. 